\title{
Two new members of mycophenolic acid family from Penicillium brevicompactum Dierckx
}

\author{
Xinhua Lu ${ }^{1,2}$, Zhihui Zheng ${ }^{2}$, Hua Zhang ${ }^{2}$, Changhong Huo ${ }^{1}$, Yuesheng Dong ${ }^{2}$, Ying $\mathrm{Ma}^{2}$, Xiao Ren ${ }^{2}$, \\ Aibing $\mathrm{Ke}^{2}$, Jiangong $\mathrm{He}^{2}$, Yucheng $\mathrm{Gu}^{1,3}$ and Qingwen Shi ${ }^{1}$
}

The Journal of Antibiotics (2009) 62, 527-529; doi:10.1038/ja.2009.54; published online 3 July 2009

Keywords: IMPDH inhibitor; mycophenolic acid; mycophenolic derivatives

Inosine-5'-monophosphate dehydrogenase (IMPDH; EC 1.1.1.205) is an essential rate-limiting enzyme in the purine metabolic pathway, catalyzing NAD-dependent oxidation of inosine- $5^{\prime}$-monophosphate (IMP) to xanthosine- $5^{\prime}$-monophosphate (XMP) of the de novo synthesis of guanine nucleotides. ${ }^{1}$ The activity of IMPDH is correlated with the growth of cells, and IMPDH has become one of the important targets of antiviral, antimicrobial, anti-cancer and immunosuppressive therapy drugs. ${ }^{2}$ Several classes of IMPDH inhibitors are now in clinical use or are under development. ${ }^{3-7}$ However, some of them suffer from a certain degree of toxicity and/or susceptibility to metabolic inactivation. ${ }^{8}$

In the program of searching for IMPDH inhibitors, the culture broth of a fungal strain Penicillium brevicompactum F01-1358 showed a strong inhibitory activity against IMPDH. Bioassay-guided fractionation of the crude extract of F01-1358 resulted in the isolation of two new mycophenolic compounds, F01-1358A (2) and B (3) (Figure 1), as well as mycophenolic acid (MPA) (1). In this study, we report the fermentation, isolation, structure elucidation and preliminary IMPDH inhibitory activity of compounds 2 and 3.

Fungus F01-1358 was isolated from a soil sample collected in the Jiangin district of Chongqing, China. The strain was identified as $P$. brevicompactum Dierckx by morphological and cultural characteristics, and was deposited in the China General Microbiological Culture Collection (accession number: CGMCC No. 2038).

The strain F01-1358 was cultivated at $27^{\circ} \mathrm{C}$ on a rotary shaker at 220 r.p.m. in the medium consisting of $1.0 \%$ starch, $2.0 \%$ glucose, $0.8 \%$ malt extracts, $0.4 \%$ yeast extracts, $0.3 \%$ bean powder, $0.13 \%$ $\mathrm{NaCl}$ and $0.15 \% \mathrm{CaCO}_{3}$ (pH 7.0 before sterilization). The 5-day-old whole broth (5.01) was adjusted to $\mathrm{pH}$ of $3.0-3.5$ by $2.0 \mathrm{~N} \mathrm{HCl}$ and centrifuged at 3000 r.p.m. for $15 \mathrm{~min}$. The mycelia were extracted with $75 \%$ acetone. After the insoluble mycelia were removed by centrifugation, the acetone was evaporated under normal pressure, the remain- ing aqueous solution was extracted with ethyl acetate and the organic layer was dried over $\mathrm{Na}_{2} \mathrm{SO}_{4}$ and concentrated under reduced pressure to yield a brown residue $(8.0 \mathrm{~g})$. The residue was subjected to a silica gel flash column chromatography and eluted with gradient of chloroform-methanol from 100:1 to 10:1. The fractions showing an inhibitory activity against IMPDH were collected and concentrated to yield a pale yellow solid. A white crystal ( $4.8 \mathrm{~g}$, compound $\mathbf{1}$ ) was obtained by recrystallization in isopropanol. Further purification of the mother solution was carried out on a preparative reverse phase (RP)-HPLC (detection: UV at $250 \mathrm{~nm}$; column: Phenomenex (Torrance, CA, USA) $\mathrm{C}_{18}, 10 \mu \mathrm{m}, 21.2 \times 250 \mathrm{~mm}$; mobile phase: $70 \% \mathrm{CH}_{3} \mathrm{CN}$-water with $0.1 \%$ acetic acid; flow rate: $\left.16.0 \mathrm{ml} \mathrm{min}^{-1}\right)$ and yielded $2(23.0 \mathrm{mg})$ and a fraction $(16.0 \mathrm{mg})$ containing compound 3. Pure compound 3 ( $4.0 \mathrm{mg}$ ) was obtained by another run of preparative RP-HPLC with a mobile phase of $65 \% \mathrm{CH}_{3} \mathrm{CN}$-water with $0.1 \%$ acetic acid.

Compound 1, a white crystal with UV $\lambda_{\max }(\mathrm{MeOH}) 249$ and $304 \mathrm{~nm}$, was identified as MPA (1) (Figure 1) by the analysis of its spectral data (electrospray ionization (ESI)-MS, ${ }^{1} \mathrm{H}$ - and ${ }^{13} \mathrm{C}-\mathrm{NMR}$ ) and by comparing them with that reported in the literature. ${ }^{9}$

F01-1358A (2) was obtained as a white crystalline powder with a molecular formula $\mathrm{C}_{20} \mathrm{H}_{26} \mathrm{O}_{6}$ (high resolution fast atom bombardment mass spectra (HRFABMS) $\mathrm{m} / \mathrm{z} 363.1808, \mathrm{M}+\mathrm{H}^{+}$, calcd for $363.1808, \Delta 0.0 \mathrm{mmu}$ error). The IR ( $\mathrm{KBr})$ spectrum suggested that 2 had a hydroxyl group $\left(3423 \mathrm{~cm}^{-1}\right)$, two carbonyl groups (1734 and $\left.1705 \mathrm{~cm}^{-1}\right)$ and an isolated alkenyl group $\left(1622 \mathrm{~cm}^{-1}\right)$. The ${ }^{1} \mathrm{H}-\mathrm{NMR}$ spectrum of 2 showed signals for a secondary aliphatic methyl group at $\delta 0.98(3 \mathrm{H}, \mathrm{d}, J=6.5 \mathrm{~Hz})$, two aromatic methyl groups at $\delta 2.05$ $(3 \mathrm{H}, \mathrm{s})$ and $\delta 1.67(3 \mathrm{H}, \mathrm{s})$, an aromatic methoxyl group at $\delta 3.67(3 \mathrm{H}$, $\mathrm{s})$, as well as a singlet at $\delta 5.14(2 \mathrm{H})$ corresponding to an aliphatic methylene with an oxygen atom attached. ${ }^{13} \mathrm{C}-\mathrm{NMR}$ and DEPT spectra confirmed the presence of 20 carbons, containing 4 primary, 5 secondary, 2 tertiary including an olefinic carbon, 7 aromatic

${ }^{1}$ School of Pharmaceutical Sciences, Hebei Medical University, Shijiazhuang, Hebei, PR China; ${ }^{2}$ New Drug Research and Development Center, North China Pharmaceutical Group Corporation, National Microbial Medicine Engineering and Research Center, Shijiazhuang, PR China and ${ }^{3}$ Syngenta, Jealott's Hill International Research Centre, Bracknell, Berkshire, UK

Correspondence: Professor Q Shi, School of Pharmaceutical Sciences, Hebei Medical University, 361 Zhongshan East Road, Shijiazhuang, Hebei 050017, PR China. E-mail: shiqingwen@hebmu.edu.cn

Received 21 April 2009; revised 29 May 2009; accepted 2 June 2009; published online 3 July 2009 
$\mathrm{R}$<smiles>[R]c1c(O)c2c(c([125I])c1OC)COC2=O</smiles>

compound

Mycophenolic acid (1)<smiles>CC=CC=C(C)CCCC(C)C(=O)O</smiles>

F01-1358A (2)

F01-1358B (3)

Figure 1 Structures of mycophenolic acid (1), F01-1358A (2) and F01-1358B (3).

Table $1{ }^{1} \mathrm{H}(500 \mathrm{MHz})$ and ${ }^{13} \mathrm{C}(125 \mathrm{MHz}) \mathrm{NMR}$ spectral data of 1,2 and 3 in $\mathrm{MeOH}-d_{4}$

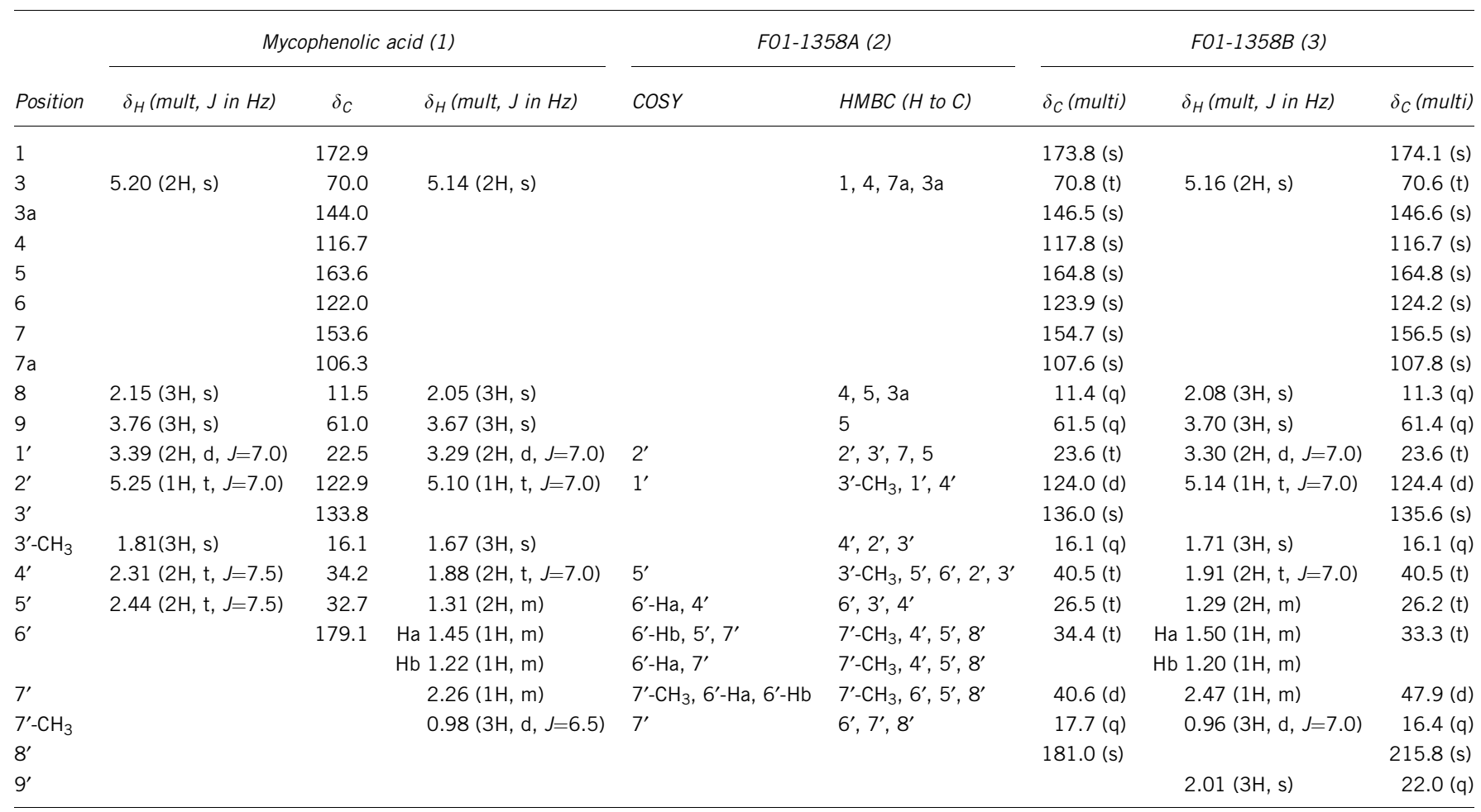

Abbreviations: COSY, correlated spectroscopy; NMR, nuclear magnetic resonance.

quaternary carbons and 2 carbonyl carbons at $\delta 173.8$ and $\delta$ 181.0. The protons of 2 connected to their respective carbons (Table 1) were assigned unambiguously through the heteronuclear multiple quantum coherence (HMQC) spectrum. The ${ }^{1} \mathrm{H}-,{ }^{13} \mathrm{C}$ - and $2 \mathrm{D}-\mathrm{NMR}$ data of $\mathbf{2}$ suggested the presence of a phthalan-1-one system with a long aliphatic chain, and indicated that 2 should be a mycophenolic derivative. ${ }^{10}$ This partial structure of phthalan-1-one was established by spectral data in comparison with those of MPA (1) and supported by its heteronuclear multiple bond coherence (HMBC) correlations from $\mathrm{H}-3$ to $\mathrm{C}-1,4,7 \mathrm{a}, 3 \mathrm{a}, \mathrm{CH}_{3}-8$ to $\mathrm{C}-4, \mathrm{C}-5, \mathrm{C}-3 \mathrm{a}$ and $\mathrm{CH}_{3}-9$ to $\mathrm{C}-5$. This result was further supported by the UV absorption at 250 and $304 \mathrm{~nm}$, which was very similar to that of MPA (1). The COSY spectrum suggested other two substructures from $\mathrm{C}-1^{\prime}$ to $\mathrm{C}-2^{\prime}$ and from $\mathrm{C}-4^{\prime}$ to $\mathrm{C}-7^{\prime}-\mathrm{CH}_{3}$. The HMBC correlations observed from $\mathrm{CH}_{3}-7^{\prime}$ to $\mathrm{C}-8^{\prime}, \mathrm{C}-7^{\prime}, 6^{\prime}$ positioned the carbonyl group at $\mathrm{C}-8^{\prime}(\delta$ 181.0). Cross-peaks from $\mathrm{CH}_{3}-3^{\prime}$ to $\mathrm{C}-4^{\prime}, \mathrm{C}-3^{\prime}, \mathrm{C}-2^{\prime}$ and from $\mathrm{H}-2^{\prime}$ to
$3^{\prime}-\mathrm{CH}_{3}, \mathrm{C}-1^{\prime}, \mathrm{C}-4^{\prime}$ in the HMBC experiment connected the two subunits through $\mathrm{C}-3^{\prime}$ and finally determined the aliphatic chain. The connection between the phthalan-1-one and the aliphatic chain was established by HMBC correlations from $\mathrm{H}-1^{\prime}$ to $\mathrm{C}-2^{\prime}, 3^{\prime}, 7,5$. Therefore, the structure of F01-1358A (2) (Figure 1) was identified as (6E)-8- (1,3-dihydro-4-hydroxy-6-methoxy-7-methyl-3-oxa-5-isobenzofuranyl)-2,6-dimethyl-6-octenoic acid.

F01-1358B (3) was obtained as a white crystalline solid using UV $(\mathrm{MeOH})$ at $\lambda_{\max } 250$ and $304 \mathrm{~nm}$. Its HRFABMS yielded a peak at $\mathrm{m} / \mathrm{z}$ 361.2007 (calcd for $361.2015, \mathrm{M}+\mathrm{H}^{+}, \Delta 0.8 \mathrm{mmu}$ error), suggesting that compound 3 has a molecular formula $\mathrm{C}_{21} \mathrm{H}_{28} \mathrm{O}_{5}$. The IR $(\mathrm{KBr})$ spectrum suggested the presence of a hydroxyl group $\left(3422 \mathrm{~cm}^{-1}\right)$, two carbonyl groups (1734 and $1717 \mathrm{~cm}^{-1}$ ) and an isolated alkenyl group $\left(1617 \mathrm{~cm}^{-1}\right)$. The UV, IR and NMR spectra of 3 showed considerable similarities to those of 2 , indicating 3 belonged to the mycophenolic derivative. With the structure of 2 established, the 
structural elucidation of $\mathbf{3}$ was relatively straightforward. Further comparison of NMR data found that the ketone group signal at $\delta$ 215.8 replaced the peak at $\delta 181.0$ (carboxylic carbonyl group) and one more methyl group $(\delta 2.01(3 \mathrm{H}, \mathrm{s}), \delta 22.0(\mathrm{q})]$ was present in 3. The HMBC correlations of $\mathrm{H}-9^{\prime}$ to $\mathrm{C}-8^{\prime}$ and $\mathrm{C}-7^{\prime}$ indicated that an acetyl group in 3 replaced the carboxylic acid group in $\mathbf{2}$ and connected to $\mathrm{C}-7^{\prime}$. The significant chemical shift change of $\mathrm{C}-7^{\prime}$ in the two compounds ( $\delta 40.6$ in 2 to 47.9 in 3 ) further supported the above-stated conclusion. This result was also supported by the IR spectrum at $1717 \mathrm{~cm}^{-1}$ instead of $1705 \mathrm{~cm}^{-1}$. Therefore, the structure of F01-1358B (3) was characterized as 6-[(2E)-3, 7-dimethyl-8-oxa-2nonen-1-yl]-7-hydroxy-5-methoxy-4-methyl-1 (3H)-isobenzofuranone (Figure 1). All the ${ }^{1} \mathrm{H}$ - and ${ }^{13} \mathrm{C}$-NMR signals of 3 were assigned unambiguously on the basis of ${ }^{1} \mathrm{H}_{-}{ }^{1} \mathrm{H}$ COSY, HMQC and HMBC spectroscopic data analysis (Table 1).

The activity of IMPDH was evaluated using the method reported by Magasanik et al. ${ }^{11}$ The recombinant human type II IMPDH was prepared in our laboratory. The enzyme activity assay was carried out in a 96-well microtiter plate by monitoring the absorbance at $340 \mathrm{~nm}$ due to the formation of NADH. Compounds 1, 2 and 3 were dissolved in DMSO and serially triple-diluted before being added to the initial assay mixture for pre-incubation with the enzyme at a final concentration of no more than $2 \%(\mathrm{v} / \mathrm{v})$. As a result, compounds 1, 2 and 3 inhibited IMPDH at the $\mathrm{IC}_{50}$ of $15.8,13.2$ and $35.6 \mu \mathrm{M}$, respectively, which indicated that the activity of compound 3 was significantly lower than that of $\mathbf{1}$ and $\mathbf{2}$. This result suggested that the carboxylic acid group that does not exist in the structure of $\mathbf{3}$ may be essential for the inhibitory activity to IMPDH.

Mycophenolic acid, discovered in 1896, attracted a lot of interest because of its variety of biological activities, such as anticancer, ${ }^{12,13}$ antivirus, ${ }^{14}$ peroxisome proliferator activated receptor- $\gamma$ agonism ${ }^{15}$ and on account of one of its derivatives mycophenolate mofetil has been developed as an immunosuppressant. ${ }^{3}$ Our findings provide two chemical entities of MPA family and their preliminary inhibitory activity to IMPDH. Further bioactivity evaluation for better understanding of their properties need to be investigated.

\section{ADDENDUM IN PROOF}

Compound 2 appears to be identical to homo-MPA reported as an impurity during the fermentation of MPA by E Gulyas et al. in the US Patent Application US 2008/254520. ${ }^{16}$

\section{ACKNOWLEDGEMENTS}

The Syngenta Postgraduate Studentship awarded to Xinhua Lu (2008-Hebei Medical University-Syngenta-2) is appreciated. We thank the colleagues from the New Drug Research and Development Center, North China Pharmaceutical Group Ltd for their kindly assistance especially Mr Dong Guo and Mrs Shiqing Zhu for NMR and MS measurements and Mr Yeying Li, Mrs Xiaolan Cui and Ying Shi for the fungus identification and fermentation.

1 Jackson, R. C., Weber, G. \& Morris, H. P. IMP dehydrogenase, an enzyme linked with proliferation and malignancy. Nature 256, 331-333 (1975).

2 Shu, Q. N. \& Nair, V. Inosine monophosphate dehydrogenase (IMPDH) as a target in drug discovery. Med. Res. Rev. 28, 219-232 (2008).

3 Hood, K. A. \& Zarembski, D. G. Mycophenolate mofetil: a unique immuno-suppressive agent. Am. J. Health Syst. Pharm. 54, 285-294 (1997).

4 Ishikawa, H. Mizoribine and mycophenolate mofetil. Curr. Med. Chem. 6, 575-597 (1999).

5 Jain, J. et al. Characterization of pharmacological efficacy of VX-148, a new, potent immunosuppressive inosine 5'-monophosphate dehydrogenase inhibitor. J. Pharmacol. Exp. Ther. 302, 1272-1277 (2002)

6 Floryk, D. \& Thompson, T. C. Antiproliferative effects of AVN944, a novel inosine 5monophosphate dehydrogenase inhibitor, in prostate cancer cells. Int. J. Cancer 123, 2294-2302 (2008).

7 Arai, M. et al. Halicyclamine A, a marine spongean alkaloid as a lead for antituberculosis agent. Bioorg. Med. Chem. 16, 6732-6769 (2008).

8 Franklin, T. J., Jacobs, V., Bruneau, P. \& Ple, P. Glucuronidation by human colorectal adenocarcinoma cells as a mechanism of resistance to mycophenolic acid. Adv. Enz. Regul. 35, 91-100 (1995).

9 Jones, C. E., Taylor, P. J., McEwan, A. G. \& Hanson, G. R. Spectroscopic characterization of copper (II) binding to the immunosuppressive drug mycophenolic acid. J. Am. Chem. Soc. 128, 9378-9386 (2006).

10 Habib, E. et al. Mycophenolic derivatives from Eupenicilliumparvum. J. Nat. Prod. 71, 1915-1918 (2008).

11 Magasanik, B., Moyed, H. S. \& Gehring, L. B. Enzymes essential for the biosynthesis of nucleic acid guanine; inosine 5'-phosphate dehydrogenase of Aerobacter aerogenes. J. Biol. Chem. 226, 339-350 (1957).

12 Domhan, S. et al. Molecular mechanisms of the antiangiogenic and antitumor effects of mycophenolic acid. Mol. Cancer Ther. 7, 1656-1668 (2008).

13 Batovska, D. I. et al. Hydroxamic acid derivatives of mycophenolic acid inhibit histone deacetylase at the cellular level. Biosci. Biotechnol. Biochem. 72, 2623-2631 (2008).

14 Hideaki, U. et al. Mycophenolic acid inhibits syncytium formation accompanied by reduction of gp120 expression. J. Antibiot. 58, 514-518 (2005).

15 Ubukata, M. et al. Mycophenolic acid as a latent agonist of PPARgamma. Bioorg. Med. Chem. Lett. 17, 4767-4770 (2007).

16 Gulyas, E. et al. Method for producing impurity level in mycophenolic acid fermentation. US 20080254520 Oct. 16, (2008). 